\title{
Erratum to: Effect of temperature and sorbitol in improving the solubility of carboxylesterases protein CpCE-1 from $\mathrm{Cydia}$ pomonella and biochemical characterization
}

\author{
Xueqing Yang $\cdot$ Yalin Zhang
}

Published online: 17 October 2013

(C) Springer-Verlag Berlin Heidelberg 2013

Erratum to: Appl Microbiol Biotechnol (2013)

DOI 10.1007/s00253-013-5236-8

The original publication of this paper contains two errors:

1. In the first paragragh of "Introduction", 2nd line (line 45), the " / $\beta$ hydrolase " was incorrectly presented and the corrected should be " $\alpha / \beta$ hydrolase"

2. In the references list, line 723 , the "Helicoverpa armigera" in the detail of "Srinivas R, Udikeri SS, Jayalakshmi SK, Sreeramulu K (2004)..... " should be "Helicoverpa armigera" 10.1007/s00253-013-5236-8.

X. Yang $\cdot$ Y. Zhang $(\bowtie)$

Key Laboratory of Plant Protection Resources and Pest Management of Ministry of Education, College of Plant Protection, Northwest A \& F University, Yangling 712100, Shaanxi, People's Republic of China

e-mail: yalinzh@nwsuaf.edu.cn 